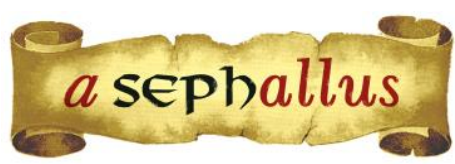

Revista aSEPHallus de Orientação Lacaniana

Núcleo Sephora de Pesquisa sobre o Moderno e o Contemporâneo

ISSN 1809 - 709 X

\title{
Estudos psicanalíticos sobre a literatura de Virginia Woolf: alguns apontamentos para futuras pesquisas sobre sua obra
}

\author{
Larissa Arruda Aguiar Alverne \\ Doutoranda em Psicanálise pela Universidade Estadual do Rio de Janeiro - UERJ. \\ Graduação e Mestrado em Psicologia pela Universidade Federal do Ceará - UFC.
} Membro em formação permanente do Corpo Freudiano Escola de Psicanálise - Seção Fortaleza.

E-mail: alvernelarissa@gmail.com

\begin{abstract}
Laéria Beserra Fontenele
Doutora em Sociologia pela Universidade Federal do Ceará. Professora Titular do Departamento de Psicologia da Universidade Federal do Ceará, Fortaleza/CE. Diretora do Corpo Freudiano Escola de Psicanálise - Seção Fortaleza.

E-mail: laeria@terra.com.br
\end{abstract}

\begin{abstract}
Resumo: Com esse artigo, pretendemos contribuir no sentido de realizar, a partir de levantamento de estudos psicanalíticos que se ocuparam da escritora Virginia Woolf, o mapeamento das principais contribuições temáticas dos mesmos e o modo como elas são examinadas pelos autores. Com isso, buscaremos refletir sobre 0 alcance desses trabalhos e em que medida eles podem confluir com outras faces da obra e da vida da autora que podem ser de interesse para futuras pesquisas em psicanálise ou que possam vir a servir de referência para a retomada de sua literatura a partir de outros recortes temáticos passíveis de exame analítico. Como critério metodológico da escolha dos estudos a serem analisados, optamos por selecionar apenas os textos de referência em nossa área de estudos, entendendo por isso, aqueles que são mais citados e comentados em trabalhos sobre a autora.
\end{abstract}

Palavras-chave: psicanálise, literatura, Virginia Woolf.

\begin{abstract}
Études psychanalytiques sur la littérature de Virginia Woolf: quelques notes pour de futures recherchessur as ouvre

Dans cet article, nous avons l'intention de contribuer dans le sens de concevoir, à partir d'une recherche basé sur des études psychanalytiques qui concernent l'écrivain Virginia Woolf, une cartographie de leurs principales contributions thématiques et de la façon dont elles sont examinées par les auteurs. Avec cela, nous allons essayer de réfléchir l'ampleur de ces travaux et dans quelle mesure ils peuvent converger vers d'autres aspects de la vie et de l'oeuvre de Virginia Woolf, ceux qui pourraient intéresser aux recherches futures en psychanalyse ou qui pourraient servir de référence pour la reprise de sa littérature à partir d'autres cadres thématiques pouvant être analysés. Comme critère méthodologique du choix des études à analyser, nous avons choisi de ne sélectionner que les textes de référence dans notre domaine d'étude, c'est-à-dire ceux qui sont le plus cités et commentés sur les œuvres de l'auteur.
\end{abstract}

Mots-clés: psychanalyse. Littérature. Virginia Woolf.

\section{Psychoanalytics studies on the literature of Virginia Woolf: notes for future researches on her work}

With this paper, we intend to contribute in realizing, through the data collection of psychoanalytic studies on the writer Virginia Woolf, a maping process of its main subjects and how they are examined by their authors. By doing this, we aim to reflect on the reach of such studies and how they may converge with other aspects of the writer's life and work, that could either be of interest for future researches on psychoanalysis or could be used as reference on studies of Woolf's literature through other themes which could be object of analytical exam. As methodological criteria for selecting which studies should be analysed, we chose only those that are referenced in our field of work, so understood those that are most quoted and comented in papers about the writer.

Key Words: Psychoanalysis, Literature, Virginia Woolf. 


\section{Estudos psicanalíticos sobre a literatura de Virginia Woolf: alguns apontamentos para futuras pesquisas sobre sua obra}

Larissa Arruda Aguiar Alverve \& Laéria Beserra Fontenele

\section{Introdução}

O modo singular com que Virginia Woolf tece as tramas de sua ficção, de como cria as suas personagens e as entrelaça de maneira lógica e original aos seus enredos ficcionais seriam motivos suficientes para interessar à psicanálise, no sentido freudiano de fazê-la avançar a partir dos indicativos do inconsciente dados por sua escritura. Sua vida cheia de perdas de entes queridos e tão conturbada e sofrida devido as suas constantes crises psicológicas se configura, também, como uma rica fonte de pesquisa para o psicanalista. Mais ainda que os aludidos aspectos, o lugar ocupado por sua própria prática da escrita como uma forma de se defender dos "choques" psicológicos que sofria, consoante suas próprias palavras e testemunhos, é também um território vasto de ensinamentos sobre a relação entre a criação, a estabilização e desestabilização no que diz respeito à estrutura psicótica. Por esses ou outros aspectos correlatos é que ela tem sido motivo de estudos tanto sobre sua obra, como sobre sua vida ou sobre a relação entre ambas.

Interessados em delimitar o alcance do horizonte desses estudos, foi que buscamos fazer o levantamento de algumas das principais produções que foram realizadas sobre Virginia Woolf a partir da teoria psicanalítica. Para empreender tal tarefa, nos valemos do critério de nos atermos aos estudos que alcançaram uma maior visibilidade, dada a frequência com que são citados como referências em relação ao tema. Desse modo, não temos a pretensão de fornecer, aqui, um inventário completo das publicações sobre a autora produzidas por tal campo de estudos. No entanto, resta a aposta de que, ainda assim, possamos, com esse trabalho, contribuir para fornecer informações relevantes para os interessados em realizar estudos em torno da escritora.

\section{Os estudos psicanalíticos sobre Virginia Woolf}

Num primeiro momento, acreditamos ser importante ressaltar que, no âmbito da Crítica Literária e de outros ramos das Ciências Humanas, destacam-se, de forma massiva, os estudos dedicados a estabelecer uma vinculação da autora com os temas do feminino e da mulher. 0 feminismo, tal como praticado por Virginia Woolf em sua relação com o feminino e o fazer literário foi um aspecto, também, bastante investigado. Em nosso país, em relação ao contexto das referidas pesquisas, merecem destaque as produções: "A crítica feminista de Virginia Woolf", de Jeferson Camargo (2009); "A escritura feita iniciação feminina: Clarice Lispector e Virginia Woolf", de Ana Luisa Andrade (1986); "Virginia Wolf e as questões do seu tempo", de Maria Luisa Heilborn (1988). Nelas, observa-se o empenho em promover a aproximação entre dados bibliográficos e autorais de Virginia Woolf com questões relativas ao feminismo e à condição social da mulher. 
No campo da psicanálise também podem ser encontrados estudos que contribuem quanto aos aspectos acima mencionados, mas o livro intitulado "Elas não sabem o que dizem: Virginia Woolf, as mulheres e a psicanálise", de autoria da psicanalista francesa Maud Mannoni (1998), revelou-se como sendo a principal referência de pesquisa sobre tal aspecto. Perseguindo a indagação freudiana acerca do que quer a mulher, contextualizando-a com a tese de que só existe uma libido masculina e de que a "anatomia é o destino", realiza seu confronto com a tese segundo a qual "ninguém nasce mulher, torna-se", de Simone de Beauvoir. O objetivo principal da autora consiste em investigar o que a obra de Virginia Woolf nos ensina sobre a mulher e o feminino, partindo da teoria psicanalítica que desvinculou o feminino da determinação biológica. No livro, a autora procede uma análise não apenas de Virginia enquanto escritora e de sua vinculação com a problemática das mulheres, mas também acerca de sua relação com o que a própria psicanálise produzira, em sua época, sobre a mesma questão. O horizonte metodológico da empreitada de Mannoni (1998) é o de que "o escritor fica sabendo pelo interior de si mesmo" o que o analista fica sabendo pelos outros" (Mannoni, 1998, p. 10). Como resultado e baseando-se em seu estudo sobre a referida escritora, a autora evoca "as raízes inconscientes do racismo antimulher" (Mannoni, 1998, p. 108).

Mannoni (1998) desenvolve o tema retornando ao próprio modo como Virginia Woolf abordou o problema das mulheres de seu tempo em relação à sua inserção social e, mais ainda, em relação à literatura, dado que esta foi uma das principais preocupações de cunho ético e político da autora britânica. $O$ interesse dela sobre a mulher e, ainda, acerca do significado de ser uma mulher é evidente desde o início de sua obra. Ela participou de forma ativa no movimento feminista de sua época e manteve contato com mulheres que fizeram história no contexto desse movimento, como Charlotte Brontë, Katherine Mansfield e Vita Sackville-West.

A biografia de Virginia Woolf será retomada, no início da citada obra, por Mannoni (1998), como subsídio para o estabelecimento de reflexões acerca de determinados fatos de sua vida e de sua relação com seus romances, sem, no entanto, utilizar-se disso para realizar uma psicanálise de sua obra. Disso, resulta a discussão de temas que assumiram destaque em sua obra, dentre os quais podemos citar, o luto, o feminismo, a homossexualidade, o desalento, os quais comparecem de forma colateral uns aos outros e não se observa uma análise mais aprofundada de cada um deles. Tais temas são aí examinados a partir de considerações sobre o processo de escrita de Virginia Woolf e do modo como se edifica a sua construção literária. Assim, a retomada dos aspectos ligados à própria existência difícil de Virginia ganha um valor metodológico em prol do entendimento sobre os possíveis liames entre a construção de sua trajetória literária, o seu diálogo com o espírito de seu tempo e o tornar-se mulher.

Um outro ponto de destaque, que consideramos relevante no contexto do estudo de Mannoni (1998), é seu interesse em desvendar os nexos entre seu processo de escrita e as particularidades de sua linguagem literária e de seu edifício ficcional. A autora afirma que Virginia 
não queria que seus personagens fossem analisados, para tanto, ela não Ihes descreveria as emoções, antes almejava suscitá-las nos seus leitores. Segundo a mesma autora, a principal dessas emoções é o luto, que deixa ao sobrevivente o tempo de sonhar a morte, protegendo-o de uma violência destrutiva. Um outro exemplo desse procedimento estético diz respeito ao afeto da tristeza, a qual ao invés de descrevê-la, desperta-a no leitor. Assim é que, no seu estilo narrativo, a autora identifica uma forma de dizer as coisas sem dizê-las, numa tentativa de dar expressão ao indizível que está, por exemplo, em jogo naquilo que há de inassimilável no trauma, conforme os ensinamentos freudianos.

Dando tratamento ao tema do feminino atrelado à vida de Virginia, Mannoni (1998) problematiza, também, a forma como ela veio a tornar-se escritora e ao lugar nisso ocupado por sua relação com sua mãe e com as palavras. Essa reflexão encontra-se sedimentada, sobretudo, na análise que faz do livro "Passeio ao farol", onde Virginia Woolf, teria dado testemunho da repetição da "elaboração do trabalho do luto, da morte, do inominável, para dar à luz ao dom de uma obra que dela se separa" (Mannoni, 1998, p. 39). Obra, na qual, cultiva uma estética que busca ultrapassar o semblante e o faz a partir de seu lugar de mulher. Lugar que, argumenta Mannoni, se reflete na escrita de sua obra e na construção de suas personagens femininas.

A questão da sexualidade na vida e nos romances de Virginia, também é motivo das reflexões de Mannoni (1988). Ela menciona o livro "Orlando" com o intuito de demonstrar como a escritora teria reivindicado, de forma sub-reptícia, a defesa da homossexualidade e de como, nele, subjaz um sonho de anulação da oposição entre os sexos, diferentemente do que realiza em seu livro denominado "Um teto todo seu", no qual sua denúncia se dirige "às barreiras erguidas entre os sexos" (Mannoni, 1998, p. 49). A psicanalista nos dá a ver o modo como, nesse último livro citado, Virginia Woolf afirma o impacto da figura materna para as mulheres e trava um debate com a concepção freudiana de sexualidade feminina, em que assume uma posição crítica, frente à mesma e em que inclina-se mais para o modo como Melanie Klein trata, então, as determinações edípicas dessa sexualidade. Crítica que será redimensionada em um período tardio de sua obra, onde, ainda segundo Mannoni (1998), ela mais se aproxima de Freud do que dele se distancia, não havendo, no entanto, perfeita confluência entre ambos. Esse aspecto pode ser melhor verificado através da fina análise que aí é feita de "Entre atos", romance terminal de Virginia. Nela, a psicanalista conclui que, ao longo da obra da escritora, existe uma oscilação entre uma identificação materna e uma identificação paterna que faz eco ao seu debate com a psicanálise e com as suas inclinações iniciais a Melanie Klein, que acabam por levá-la a Freud, a despeito de sua própria ambivalência. Se ao princípio de sua trajetória, Virginia Woolf tratava de discutir a descendência materna, em "Entre os atos" ela trará à tona a "Sociedade dos Pais". Tal movimento vai na direção de sua tomada de posição contra a ideologia nazista que glorifica a maternidade biológica. 
Uma variação da temática do feminino pode ser encontrada no livro de Vanessa Curtis (2005), intitulado "As mulheres de Virginia Woolf". Nele, ela nos oferece uma rica e minuciosa descrição acerca do tipo de relação que Virginia manteve com as mulheres de sua vida. A autora defende a importância que as figuras femininas desempenharam em diferentes momentos da vida da escritora e sua tese é a de que a sua ligação afetiva com elas, desempenhava um papel fundamental no controle de suas crises psicóticas. A autora reconstrói o caso de Virginia - ao modo biográfico - tendo por foco, as relações íntimas que Virginia Woolf estabelecia com as mulheres e o efeito que elas tiveram sobre sua vida e obra, dado que muitas dessas mulheres serviram de inspiração à criação de personagens presentes em suas principais criações literárias.

Curtis (2005), no início de seu livro, traz à tona detalhes não tão conhecidos da infância de Woolf e, nesse momento, descreve três mulheres determinantes em sua vida: sua avó, Maria; sua mãe, Julia, e sua meia-irmã, Stella. Dado o modo de ser altruísta de cada uma delas, todas são, nessa descrição, figuradas como "os anjos da casa". Por tal modo de ser, tais mulheres serviam, paradoxalmente, de marcos ideais à constituição subjetiva de Virginia e de fonte de assombro pelo resto de sua vida.

O livro prossegue com o exame da relação da autora inglesa com uma das principais personagens de sua vida: sua irmã, Vanessa. Ela inspirava respeito e inveja em Virginia, tanto por se diferenciar das outras mulheres presentes em sua existência, ao ter um posicionamento mais autoritário e independente, quanto também por ser ela artista, o que gerava uma relação de admiração e, ao mesmo tempo, de competição entre as duas. Vanessa foi uma das mulheres mais importantes da vida de Virginia e esteve com ela em todas as suas posteriores crises e cuidou dela até o momento de sua morte. Não era também à toa que, durante os momentos de crise, Vanessa era o principal alvo das agressões de Virginia. A descrição de Curtis (2005) dos principais pontos da relação das duas, baseada em biografias e correspondências, aparece como um dos pontos altos de seu estudo.

Posteriormente, a relação de Virginia com os seus declarados grandes amores é destacada pela autora. Nesse momento de sua análise, Curtis (2005) explora os relacionamentos amorosos de Woolf com Violet Dickinson e Vita Sackville-West. Ao descrever os detalhes dessas suas duas relações íntimas, a autora realça a dependência que Virginia Woolf estabelecia com as mulheres e de sua exigência de que elas the dispensassem um cuidado quase maternal. Em diversos momentos, a autora argumenta que Virginia precisava de suas relações amorosas com as mulheres tanto para a estabilização de suas crises quanto para conseguir escrever. E que, no momento em que se via abandonada ou esquecida por elas, tendia ao desespero.

Curtis (2005) debruça-se, ainda, sobre as amizades de Woolf com Ottoline Bentinck e Katherine Mansfield, ambas, vinculadas à literatura e à alta classe média londrina. Nesse caso, tais amizades estavam bem mais relacionadas ao seu posicionamento como escritora, não se tratando, dessa forma, de um relacionamento sensualmente amoroso. Ambas foram buscadas por Virginia 
para servirem de leitoras de diversas de suas obras antes que fossem publicadas e suas opiniões eram extremamente valorizadas por ela.

O livro culmina com a descrição da ligação entre Virginia e Ethel Smyth, sua última grande amizade. Ethel tinha 72 anos e Virginia 48 anos quando as duas se conheceram. Segundo Curtis (2005), o relacionamento entre ambas foi bastante tortuoso, o que atribui ao fato da nova amiga se portar, em relação à Virginia, de modo extremamente crítico, contrariando à demanda que ela costumava direcionar às mulheres, no sentido que as mesmas adotassem, em relação a ela, uma posição materna. Apesar de tais intempéries, a amizade entre elas durou até o suicídio de Virginia. Assim, em síntese, o texto de Curtis (2005) oferece ao leitor uma jornada pelos relacionamentos mais íntimos de Woolf em que busca retratar o lado da autora enquanto filha, irmã, amante e amiga e o modo como tais experiências se refletem em sua literatura.

A relação de Virginia Woolf com a escrita de suas obras e com seus períodos de loucura também foi alvo de pesquisas a partir do ponto de vista psicanalítico. Woolf se referia à escrita de seus textos como o que lhe dava sua simetria, seus livros eram fruto de um dever de escrever que se impunha a ela de forma imperativa. Neles, a autora deposita uma íntima e extraordinária descrição do seu sofrimento psíquico.

É sobre a relação entre a função ocupada por sua literatura na lida com sua loucura que o livro, lançado em 2011, "Virginia Woolf: L'écriture refuge contre la folie" vai se ocupar. O seu formato é de coletânea, dirigida por Stella Harrison com a colaboração de Nicolas Pierre Boileau, Luc Garcia, Monique Harlin, Sophie Marret, Ginette Michaux, Pierre Naveau, Michèle Rivoire e, principalmente, Jacques Aubert. Esse último trabalha atualmente com a tradução para o francês dos escritos de Virginia Woolf e suas ligações com a teoria psicanalítica. De uma forma geral, os estudos presentes nesse livro apresentam em comum, o objetivo de realizar aproximações entre o processo de escrita de Virginia Woolf e os diversos momentos, em que, ao longo de sua vida, experimentou severas crises psicóticas. Em relação a isso, os textos aí presentes orbitam em torno da categoria do real. 0 real em jogo em sua escritura e em suas crises é trabalhado, sobretudo, em relação a uma de suas principais obras, "Mrs. Dalloway". Assim, a dimensão clínica da psicose ganha centralidade no estudo de todos os autores citados, conforme observaremos.

No próprio título que dá ao seu trabalho "Entre les actes, fiction ou réel?", Monique Harlin (2011) dá o tom do problema que levanta e examina, qual seja o contexto em que Virginia Woolf escreveu seu último romance, "Entre os atos" (1938), publicado postumamente. A autora faz uma necessária descrição do enredo do romance, relacionando-o a eventos que teriam tido lugar na vida de Virginia nos momentos concomitantes à sua criação e que, de acordo com a autora, tiveram uma enorme influência sobre a escrita dele. Nesses termos, constata a autora, haver entre o enredo de "Entre os atos" e a experiências pessoais de Virginia um elo muito particular. Ela também indaga se a escrita desse romance não teria sido uma espécie de aventura literária para Woolf. Sua questão consiste em elucidar se a história do livro não teria funcionado para ela, de 
uma forma compensatória, ao modo de uma sublimação, em face a seus dilemas existenciais e ao seu sofrimento psíquico. Destaca-se para nós, no contexto dessa análise de "Entre os atos", uma valiosa descrição que a autora faz do fato de que, ao longo do romance, por diversas vezes, o significante "perfeito" será associado ao significante da "morte".

De acordo com Harlin (2011, p. 33), "L'amour parfait est celui des morts. Ainsi cette idylle imaginée est-elle un amour mort" ${ }^{\prime 1}$. Para ela, uma plenitude absoluta é o que Virginia tenta reproduzir em seu romance, seja através do amor ou da morte, sendo que os dois se fundem em diversos momentos da narrativa. Em última instância, demonstra que "Entre os atos" é um romance sobre a morte e o amor.

Tendo por marco a teoria psicanalítica, um outro aspecto destacado por Harlin (2011) é a forma como o processo de escrita de Virginia Woolf possuía um ritmo próprio que estaria relacionado aos fragmentos de sua própria história, de sua infância, de sua sexualidade e de seu sofrimento. Ao final de sua análise, Harlin (2011) aborda os últimos momentos da vida de Virginia Woolf, o envio de "Entre os atos" para seu editor e a sua última correção, bem como a escrita das cartas para seu marido e para sua irmã, figurando-os como sendo os últimos semblantes que Virginia concede à vida. Segundo a autora, nesse momento, a fronteira entre a ficção e a realidade se dissipou e deixou de existir, as palavras teriam perdido o seu poder de manter a realidade, de forma que teria se dado o triunfo do amor/morte. Por fim, resta a suposição: seria a escolha do ato suicida a escolha última do sujeito? Em síntese, a autora argumenta que a angústia provocada pela escrita dos últimos parágrafos de "Entre os atos" teria feito ruir a proteção que lhe garantia o seu processo de escrita e o valor imaginário de sua literatura e da fantasia, o que seria ilustrado pelas cortinas que fecham ao final dos atos do romance.

O texto escrito por Sophie Marret (2011), intitulado "Le creux de la vague", tem por objeto de análise o romance "As ondas", considerado por muitos de seus estudiosos como a obra mais experimental de Virginia Woolf e até mesmo como sendo sua obra-prima. O estudo romance é empreendido tendo por ponto de partida a proposição de que Woolf descrevia seus processos depressivos em suas cartas e diários como "ondas", de forma que tal significante parece remeter a algo que é da ordem do sinistro, do horror. Considera, além disso, que, um pouco antes de seu suicídio, Virginia se refere ao seu processo de escrita associando-o com experiências de êxtase, experiências da e com a linguagem que a protegem contra o real invasor e servem para apaziguar um gozo ilimitado. Para Marret (2011), a escrita de Virginia visa apreender no significante, e mais além do semblante da imagem, o real que lhe é comumente roubado. Tal tentativa haveria por substrato o que há de inassimilável na própria pulsão. Assim, tratar-se-ia de algo que sua sensibilidade a faz captar, mas algo que não consegue precisar o que seja. Um outro aspecto, concernente ao mencionado reencontro de Virginia com o real, que é salientado no citado estudo, é o paralelismo do sentimento de extravio de si mesma - de sentir-se estrangeira de si mesma com o sentimento de completude presente em suas experiências estáticas originais. 
Ainda de acordo com Marret (2011), o romance "As ondas" parece ter sido uma consequência da escrita de "Ao farol", no qual a questão do luto do objeto se faz presente. Ao defender o argumento de que em "As ondas" se daria, na escrita de Virginia, a assunção da morte, introduz uma discussão acerca existência de uma íntima relação entre amor e morte nesse último romance citado. Por fim, nesse estudo, é demonstrada como se dá a operação pulsional que consiste em aproximar a morte do significante "amor", o que ocorreria, segundo a autora, em todo este romance: "La transparence du signifiant, du roman, reste ouverte sur le réel"² (Marret, 2011, p. 69).

Partindo dos argumentos de uma corrente da Crítica Literária americana que se propôs a reler os textos de Virginia Woolf a partir das teorias do traumatismo e, mais precisamente, dos testemunhos de suas vítimas, é que Nicolas Pierre Boileau (2011) constrói um percurso analítico que consiste em desconstruir as teses dessa escola, as quais qualifica de estarem cegas por seu saber. Opondo-se de forma fervorosa e rigorosa às mesmas, as acusa de confundirem o impossível de dizer do real com o silêncio.

Boileau (2011) intitula seu reexame das relações entre a escrita de Virginia e o traumatismo de "Les 'mots ordinaires' et la littérature face au réel". Nele, adota uma outra perspectiva acerca da relação da literatura de Virginia com o trauma, pois não o considera como um "a priori" de sua obra. Sua análise tem por fonte, sobretudo, os diários de Virginia Woolf e demonstra que, neles, as lembranças que Virginia menciona como as mais conservadas em sua memória são aquelas por ela nomeadas de "traumáticas". Segundo ele, o trauma é tratado por ela como uma causa, como uma explicação que vale para tudo, sendo em seu livro "Momentos de ser" que ela teria elaborado uma teoria do trauma, a qual ela nomeia de "choques" e, por meio da qual, teria tentado explicar o caráter repetitivo e definitivo de suas crises. Assim, em "Momentos de ser" ela nos convidaria, ainda segundo Boileau (2011, p. 81), a reler o trauma como uma construção do sujeito que seria feita para tratar de uma ferida que as palavras não conseguiriam fechar.

Destacamos, que, o aspecto original do trabalho de Boileau (2011) consiste em demonstrar que, para Virginia Woolf: "Les mots banals de la vie quotidienne sont un écran au réel dont il n'est pas facile de se débarrasser" ${ }^{\prime 3}$ (Boileau, 2011, p. 85). O referido estudo culmina com a reafirmação da importância da teoria woolfiana sobre o trauma, onde o mesmo evento, o mesmo trauma é assim por ela reescrito, diversas vezes, tanto em sua biografia quanto em suas ficções, em uma busca de circunscrever o indizível. Woolf mostra-nos, entretanto, a existência de um resto que não pode ser bordeado, fala-nos, sobretudo, como a escritura não pode dar conta do real da experiência.

Pierre Naveau (2011) em "Le drame de Septimus et Lucrezia" discorre sobre dois personagens do romance de Virginia Woolf intitulado "Mrs. Dalloway". O autor inicia seu texto comparando as escritas de Virginia e de Joyce e defendendo a tese segundo a qual os dois autores 
se aproximariam por terem o real - em seu sentido lacaniano - como ponto de partida de suas escritas. Tanto Woolf quanto Joyce teriam respondido ao choque que o reencontro com o real provoca, e isso na medida em que um saber sobre esse real lhes falta. Seria exatamente essa falta que os dois escritores teriam buscado suprir. Com a ressalva de que, para Virginia, escrever teria sido, principalmente, uma defesa, com palavras, contra o real que lhe tenta aprisionar com a sua ferocidade.

Em seguida, Naveau (2011) inicia uma minuciosa análise do romance "Mrs. Dalloway", em que descreve os personagens principais do romance: Clarissa Dalloway e Septimus Warren-Smith. Começa por fornecer uma descrição da personagem Clarissa, porém, o faz com o propósito de que, a posteriori, possa compará-la a Septimus, o personagem sobre o qual de fato, pretende escrever detalhadamente. Naveau (2011) tem por argumento que a questão do sintoma, para os diferentes personagens do romance, está relacionado ao impossível de dizer e viver do amor. Para ele o livro é representativo do momento, no contexto da obra de Woolf, em que o tema da morte e do amor aparecem conjugados.

"Une suppléance fragile: les refuges de Clarissa Dalloway", de Ginette Michaux (2011), foi outro estudo igualmente voltado para o romance "Mrs. Dalloway" e que parte do princípio de que a referida obra é, sobretudo, um escrito sobre a morte e o suicídio. Michaux (2011) considera que Virginia, depois de sua adolescência, iniciou uma batalha contra a invasão do real e que sua escritura teria sido a única arma que encontrou para lutar contra isso. Tal batalha teria se dado por meio de uma busca do semblante, a qual teria sido mediada por sua criação literária de mundos e pessoas inventadas (tonalidade fantasiosa de toda fiç̧ão) e, a partir disso, de seu intento de produzir um sinthoma (no sentido que Ihe atribui Lacan (2005) em seu seminário sobre James Joyce: uma criação que teria a função de fornecer a estabilidade do nó entre o real, do simbólico e do imaginário). A psicanalista defende, também, que a lógica que se destaca da obra de Virginia tem muito a nos ensinar sobre prática analítica, na medida em que permite verificar e aprofundar conceitos fundamentais à experiência clínica. Para ela, a ficção de Virgínia seria ela mesma uma construção analítica no sentido de que evocaria a própria lógica do inconsciente e não necessitaria de forma alguma de uma psicanálise aplicada a ela.

Michaux (2011) retoma, nesse contexto, o conceito lacaniano de "letra" que será compreendida como uma instância do significante, enunciação que marca, por um lado, um lugar desejante singular frente ao Outro e, por outro lado, funciona como um traço de uma borda que, por sua vez, ao modo de um litoral demarcaria as fronteiras entre o sentido e o sem sentido, entre o saber e o gozo. Ao proceder a análise de "Mrs. Dalloway", a autora toma a personagem de Clarissa como principal foco. Segundo ela, o romance de 1925 põe em cena um saber sobre a estrutura da linguagem, bem como constrói figuras de alteridade que propiciam a emergência da personagem Clarissa, como alguém que o simbólico não separa de seus semblantes. Surge, assim, uma Clarissa que, sem arrimo, parece ser levada pelas "ondas da vida". 
A questão do amor irrompe como um importante elemento do estudo, chegando a autora a afirmar que, em "Mrs. Dalloway", o amor é destrutivo. Para Clarissa, a personagem principal, o amor Ihe abre um abismo, pois representa o que o desejo do Outro tem de incognoscível, e isso provoca o surgimento de demandas persecutórias. A palavra de amor não faria suplência ao impossível em jogo relação sexual. Para discutir esse aspecto, Michaux (2011) vai deter sua análise na relação de Clarissa com seu esposo Richard. Michaux (2011) realiza uma comparação entre "Mrs. Dalloway" e a peça de Shakespeare "Hamlet", onde, dentre outros aspectos, destaca-se o momento em que é abordada a questão da morte. Diz que a morte apenas separa-se da vida como um quarto se separa de outro, a própria canção fúnebre é enganadora. As fronteiras entre a vida e a morte, nas duas obras, se mostram porosas.

Outras publicações relevantes foram encontradas acerca da mesma aproximação entre Virginia Woolf, sua escrita e sua loucura, dentre as quais destacamos "Virginia Woolf entre la maladie et l'écriture" de Bibiana Morales (2008). Em seu ensaio, a autora retoma as próprias indagações de Virginia em torno de sua doença e da escrita de seus romances. A partir disso, emerge a indagação acerca de como Virginia se serviria de sua loucura para fazer arte, na medida em que, na feitura dessa, ela deseja transmitir seu senso estético e não seu delírio. Sua tese é a de que a escrita da romancista tinha para ela um valor terapêutico, onde se verificaria a ação de uma defesa contra o efeito mortífero dos fenômenos elementares de sua psicose. Em outras palavras, a defesa consistia em transferir para a escrita, a angústia aterradora vivenciada em seus momentos de crise. A autora adverte, no entanto, que essa operação de suplência, por meio da escrita, à sua psicose conseguia apenas parcialmente a sua meta, por isso mesmo ela viria, em certo momento, a falhar.

Retorna, ainda, a um dado curioso sobre a relação de Woolf com seu trabalho como escritora: no momento do envio de cada livro para a edição, ela não os revisava, não lia suas obras. O momento de receber uma resposta do Outro sobre seus trabalhos era de extremo sofrimento para a autora e correspondia, em geral, à intensificação de estados de insônia, dores de cabeça, dificuldade de escrever, dentre outras sensações de tonalidade melancólica. Morales (2008), assim observa que, paradoxalmente, sua escrita tinha tanto o poder de apaziguar seus estados de crises, quanto o poder de lançá-la num abismo. Observa essa autora que, para dar conta desse duplo efeito de sua escrita e para que essa fosse possível, a própria Virginia passa a fazer a distinção dos seus livros em dois tipos: os "sérios" e os de "férias". Momentos de ser e de não-ser. Os romances com cuja escrita Virginia experimentava mais alívio ou prazer eram os que a desorganizavam. Os demais eram os que Ihe serviam à reamarração do que havia se desfeito em seu mundo.

A questão da morte é retomada também por Morales (2008), quando fala de um luto impossível de ser elaborado por Virginia. A morte vai ser uma questão que Woolf não cessa de abordar em seus romances, a partir de um ideal mortífero de transparência total. A morte encontra 
seu fundamento no real, uma morte que atravessa toda a vida da autora como uma onda. Conclui sua reflexão em torno da função da doença na vida da escritora, e ela se põe entre a criação e os limites da escritura. Entre esses dois, observa que o corpo encontra um lugar de interseção, a escritura cria corpo com a finalização de um texto. Virginia, segundo ela, existe a partir de um corpo feito de letras. Dessa forma, a citada autora conclui que a escrita da ficcionista funcionava como produtora de um contorno que servia para traçar o corpo não simbolizado pelo Outro, como suplência ao Nome-do-Pai que não operou.

Embora não aprofunde a questão, Morales (2008) abre, ainda no contexto de seu estudo, o espaço para que se reflita acerca do lugar ocupado pelo personagem Septimus de "Mrs. Dalloway", no sentido em que pode ser observada uma certa aproximação entre tais vivências proporcionadas, ao mesmo tempo, por sua criação literária e por sua loucura. Ele teria servido à Virginia Woolf para realizar o confronto entre razão e loucura.

Outro ensaio segue uma direção similar a esse acima repertoriado. Trata-se de "Virginia Woolf, a escrita, o ser, o real", de Stella Harrison (2012), no qual a autora toma como baliza, a coletânea a que anteriormente nos referimos, qual seja: "Virginia Woolf, a escrita como refúgio contra a loucura". Nesse livro, busca elementos que permitem que ela retome a questão que busca melhor esclarecer e que consiste em procurar discernir a razão por que Virginia precisava constantemente reinventar sua escrita. O texto de Harrison (2012) orbita, principalmente, em torno da hipótese de que as últimas obras de Virginia eram, em verdade, um pedido de socorro. Segundo ela, em determinado momento da vida da escritora, o real, simbólico e o imaginário pareciam se fundir, e a pulsão de morte corria desenfreada, remetendo-a a uma pulverização e fragmentação dos objetos pulsionais. Sua conclusão é a de que a língua de Virginia Woolf deixou de avançar sobre o real.

Ainda no que concerne à relação de Virginia Woolf, sua loucura e a escrita de suas obras, destacamos o artigo "Virginia Woolf: entre sonhos", de Elizabeth da Rocha Miranda (2010), que se ocupa da função da escrita como suporte e de seu efeito na psicose, a partir da vida e da obra de Virginia Woolf. Miranda (2010) demonstra como a escrita de Virginia era um recurso utilizado para cifrar aquilo que, por não ter caído sob a barra do recalque, retornava para ela como real. Amparando-se em Lacan, considera que a escrita é um fazer que dá suporte ao pensamento e que a escrita - enquanto registro do real do significante - trata do que se ouve do significante. Assim, observa que a escrita ecoa de "lalíngua", que, para Virginia, retorna no registro do real. Essa se encontrava presa na escrita, parecendo existir apenas como uma letra que não desliza entre significante e significado. Na conclusão de sua análise, Miranda (2010) afirma que Virginia (ao contrário de Joyce), apesar de tão relevante obra, não conseguiu que sua escrita produzisse uma suplência à foraclusão do Nome-do-Pai, daí seu destino último ser o mergulho nas águas do Rio Ouse. 
Outro recorte, a partir do qual Virginia Woolf é tomada como objeto de pesquisa, foi o da relação de sua escrita com seu suicídio. No campo da psicanálise, a autora Lenita Bentes (2014), no texto "Escritores criativos e a passagem ao ato suicida", pesquisou acerca dos limites e da eficácia da função da escrita como produtoras de estabilização psíquica nas psicoses. A autora propõe que, no caso de certos escritores, uma vez ultrapassado certo limite imposto pela própria escrita, tal ultrapassagem levaria ao rompimento definitivo de seus laços com o Outro. 0 entendimento da autora é o de que no momento que um autor escreve, ele desaparece. Desse modo, morte e escrita confluem uma com a outra. Assim, segundo eles, o escritor escreve para si mesmo, logo, desaparece como sujeito, uma vez que não há quem autentique seu ato. Ressalta, por outro lado, que escrever pode operar como uma mediação do prazer com o gozo, aliviando, mesmo que de forma parcial, a angústia ou o sintoma.

Em seu texto, Bentes (2014) tomou como fontes de sua análise as biografias de Virginia Woolf e do escritor Stefan Zweig. Assim, a partir da primeira, retoma o depoimento de Virginia acerca de seu trabalho de criação literária, no qual dizia que quando terminava um trabalho, sentia-se invadida por uma onda avassaladora, indicando certa estabilização do gozo quando da realização de sua escrita. No entanto, observa que, na impossibilidade de uma invenção sintomática, de um savoir-faire, para Virginia, o laço estabelecido com a linguagem não parecia ser suficiente para garantir a amarração dos registros do real, do simbólico e do imaginário, a partir do qual ela se sustente mais tempo. Na psicose, o impasse com o significante $\left(\mathrm{S}_{1}\right)$, que sustenta a seriação da cadeia significante, promove uma primazia do objeto e perturba o campo da realidade. A conclusão de Bentes (2014) é: em determinado momento, as possibilidades de criação metafórica atingem o efeito de precipitação e deixam o sujeito no vazio, sem mediação simbólica. Com isso, o sujeito faz-se objeto e cai, por não poder esperar mais do laço com a linguagem.

\section{Considerações finais}

Mediante a análise das contribuições psicanalíticas sobre Virginia Woolf acima descritas, ressaltamos que, mesmo considerando suas especificidades, todas apresentam um elemento que Ihes é comum: a consideração da obra de Virginia Woolf como sendo portadora de uma estrutura. Neste sentido, os elementos em jogo abririam espaço para o empreendimento de reflexões com o potencial de fecundar o campo psicanalítico, levando-o ao avanço no entendimento de alguns dos enigmas ou dificuldades precipitados pela prática psicanalítica, os quais, esses sim, variam para cada um dos estudos aqui considerados.

Quanto às diferenças e/ou especificidades relacionadas com o conteúdo das publicações psicanalíticas enfocadas, detectamos a ocorrência de quatro temáticas principais sobre as quais elas se debruçaram: a relação de Virginia Woolf com a problemática do feminino; o liame entre sua escrita e a sua lida com a manifestação de sua psicose; as particularidades de seu estilo e de sua relação com as determinações de sua existência e, ainda, e o sentido que assume o seu suicídio, 
de uma forma geral, e da relação desse com a escrita de suas obras terminais.

Observa-se, ainda, que dentre os citados estudos, a maior parte deles privilegia a questão da psicose como tela de fundo de suas análises, exceto aqueles de autoria de Maud Mannoni e Vanessa Curtis, nos quais a psicose é apenas um dado correlato aos temas centrais de seus estudos. Nos demais, a psicose serve para emoldurar outros vieses de sua obra que ganham expressividade, como por exemplo: seu processo criativo; sua dificuldade de fazer lutos e a incidência disso em sua escrita; sua relação com as mulheres; o lugar do complexo materno e paterno em sua vida e seus ecos em seu fazer literário; o lugar do trauma em sua vida e em sua escrita, dentre outros.

Observamos, no entanto, que mesmo diante de uma ocorrência significativa de estudos dedicados à relação entre sua escrita e sua psicose, isso não significa que esse aspecto tenha alcançado a sua saturação, havendo ainda nuances que, ainda, poderiam ser, neste âmbito de estudos, exploradas. Um dos exemplos disso é o estudo comparativo da função diferencial da obra de Virginia e da de Joyce no que toca à questão da suplência na psicose. Mesmo que tenhamos encontrado trabalhos que examinaram diretamente a questão ou a tenham tratado de forma secundária, constatamos que tal comparação poderia ainda seguir outras trilhas, tais como: o lugar da experiência extática em contraposição ao lugar da epifania e do dizer magistral, respectivamente na obra de um e de outro; o que ambos poderiam ensinar sobre os alcances da invenção e da criação quanto à ligação entre o significante e o corpo pulsional; o exame da relação entre corpo e escrita, tendo por base a categoria de letra, nos dois autores e quais as consequências disso para uma discussão mais rigorosa sobre a clínica das psicoses e a questão da estabilização e da suplência; uma discussão sobre o amor na obra de ambos ou em suas vidas, bem como outras derivações quanto à sexualidade; o lugar do complexo paterno na escrita de ambos, a relação entre a angústia, o sentido e o sem sentido e etc.

Os textos de Morales (2008), Miranda (2010) e Harrison (2012) ocupam-se diretamente das particularidades da escrita de Virginia em sua aproximação com a forma de regular com suas crises psicóticas e da função da mesma para a amarração entre os registros do real, do simbólico e do imaginário, bem como do predomínio de uma invasão do real em sua existência. Entretanto, deixam como temas não suficientemente explorados: o lugar ocupado nisso pela sua relação à diferença sexual; a relação da autora com o Ideal; o lugar dos duplos imaginários em sua vida; as variações em seu próprio processo de escrita e a invenção de métodos de composição literária em distintos momentos de sua vivência das crises; a angústia e o gozo em sua escrita, dentre outros aspectos que poderiam ser detectados por outras possíveis leituras do material examinado.

Constatamos também que todos os artigos ou ensaios presentes na coletânea "Virginia Woolf: l'écriture, refuge contre la folie" estão centrados na categoria do real e deles se destacam duas importantes questões essenciais à compreensão de sua obra, mas também de sua loucura: o lugar da morte e o do amor em sua vida e obra. Porém não há, um estudo mais geral sobre esses 
dados no contexto geral da obra de Virginia, sendo mais enfocada pelos autores a relação entre morte e o luto e entre a morte e o trauma em obras pontuais como "Passeio ao farol", "Mrs. Dalloway", dentre outros. Eles abrem o espaço para o aprofundamento da presença da morte em sua vida e de sua incidência literária, bem como para o estudo de efeitos estéticos presentes nos romances da ficcionista que remeteriam ao lugar da morte. À parte disso, a questão do amor na história da literatura de uma forma geral e na sua literatura de forma particular, bem como a relação entre o amor e o problema da diferença sexual em sua trajetória são temas dignos de um aprofundamento que muito pode ensinar à clínica psicanalítica.

Além do citado conjunto de estudos, verificamos também que, nas pesquisas que buscam se ocupar de temas como os episódios de loucura e, principalmente, sobre a escrita das obras de Woolf, certos comentários sobre a morte, tanto como fato da escrita de Virginia, como enquanto um espectro que rondava a vida da mesma, parecem inevitáveis. Dessa forma, o significante da morte sobressaiu-se durante nossas pesquisas como digno de um percurso de pesquisa mais rigoroso, dado que o mesmo se precipita como um dado reiteradamente mencionado, mas que não é levado às últimas consequências analíticas.

Por sua vez, o estudo de Bentes (2014), de Morales (2008), de Miranda (2010) e de Harrison (2012), uma vez postos em diálogo, por também tomarem a psicose por central, apontam, entretanto, para a necessidade de uma leitura diferenciada da obra da autora que permitiria nos guiar para a relação entre sua própria escrita e dados da estrutura. Consideramos a virtualidade desse caminho, um campo fértil para discussões comparativas entre a escrita, o corpo, a criação e a sublimação não só em sua relação com a psicose, mas também do que ela ensinaria sobre a própria constituição psíquica dos sujeitos humanos em geral.

Por último, quanto ao trabalho de Maud Mannoni sobre Virginia, ressaltamos que apesar de se deter, de forma mais precisa, nas questões relacionadas à sexualidade feminina, ao feminino e à condição da mulher na cultura, ele abre uma série de janelas que tornariam possíveis futuras pesquisas sobre a escritora. Tratam-se de temas que são abordados de forma correlata ao seu objeto do estudo, no sentido de permitir a ampliação de seu vislumbre, mas que eles mesmos não ganham um exame e uma discussão de maior densidade. Dentre os mesmos, destacamos: o problema do luto e do desalento como estados afetivos que remontam à questão da identificação nas psicoses; as características particulares com que se dá a homossexualidade de Virginia mencionadas, mas não aprofundadas pela autora -, aliado ao fato de que "Orlando" é um importante testemunho a ser levado em consideração para um tal estudo; a ambivalência amorosa da autora em relação ao pai e à mãe; o lugar do afeto da tristeza em seu procedimento estético.

Mesmo diante de uma pesquisa que limitou sua amostra a uma quantidade precisa de textos sobre a escritora Virginia Woolf, pudemos ver que sua análise foi fecunda no sentido de demonstrar o quão expressivas e múltiplas são as sugestões deixadas por eles no sentido de contribuir para a construção e para o exame de outros possíveis problemas de pesquisa que 
possam trazer novas contribuições não só ao tema, mas também à teoria e a clínica psicanalíticas.

\section{Notas:}

${ }^{1}$ Artigo elaborado a partir da Dissertação de Mestrado intitulada "A Morte e o Real na literatura de Virginia Woolf", defendida no Programa de Pós-graduação em Psicologia da Universidade Federal do Ceará em 2017, sob orientação da Profa. Dra. Laéria Beserra Fontenele e financiada pela CAPES/CNPQ.

${ }^{2}$ Tradução livre "O amor-perfeito é o amor dos mortos. Dessa forma, esse idílio imaginário é ele mesmo um amor morto".

3 Tradução livre "A transparência do significante, do romance, permanece aberta para o real".

${ }^{4}$ Tradução livre "As palavras banais da vida cotidiana são uma tela para o real, do qual não é fácil de se livrar".

\section{Referências Bibliográficas}

Bentes, L. V. G. (2014). Escritores criativos e a passagem ao ato suicida. Psicanálise \& Barroco em revista, 12(2), pp. 181-206.

Boilleau, N. P. (2011). Les "mots ordinaires" et la littérature face au réel. In S. Harrisson \& J. Aubert (Orgs.). Virginia Woolf: L'ecritures, refuge contre la folie (pp. 77-99). Paris: Michèle.

Curtis, V. (2005). As mulheres de Virginia Woolf. São Paulo: Girafa (Obra original publicada em 2002).

Harlin, M. (2011). Entre lês actes, fiction ou réel? In S. Harrisson \& J. Aubert (Orgs.). Virginia Woolf: L'ecritures, refuge contre la folie (pp. 17-51). Paris: Michèle.

Harrisson, S. \& Auberte, J. (2011). Virginia Woolf: L'ecritures, refuge contre la folie. Paris: Michèle. Harrison, S. (2012). Virginia Woolf, a escrita, o ser, o real. Opção Lacaniana online, 9, pp. 1-11. Recuperado em 14 de julho de 2015, de $<$ http://www.opcaolacaniana.com.br/pdf/numero_9/Virginia_Woolf_a_escrita_o_ser_o_real.p $\mathrm{df}>$.

Lacan, J. (2005). O Seminário, livro 23: o sinthome. Rio de Janeiro: Jorge Zahar (Seminário original proferido em 1975-1976).

Mannoni, M. (1999). Elas não sabem o que dizem: Virginia Woolf, as mulheres e a psicanálise. Rio de Janeiro: Jorge Zahar (Obra original publicada em 1998)

Marret, S. (2011). Le creux de la vague. In S. Harrisson \& J. Aubert (Orgs.). Virginia Woolf: L'ecritures, refuge contre la folie (pp. 53-76). Paris: Michèle.

Michaux, G. (2011). Une suppléance fragile: les reguges de Clarissa Dalloway. In S. Harrisson \& J. Aubert (Orgs.). Virginia Woolf: L'ecritures, refuge contre la folie (pp. 157-183). Paris: Michèle. 
Miranda, E. R. (2010). Virginia Woolf: entre sonhos. Trivium, 1, pp. 265-275. Recuperado em 29 de julho de 2014, de <http://www.uva.br/trivium/edicao2/artigos-tematicos/5-virginia-woolfen>.

Morales, B. Virginia Woolf: entre la maladie et l'écriture. Psychanalyse, 12, pp. 35-40. Recuperado em 26 de fevereiro de 2015 de <www.cairn.info/revue-psychanalyse-2008-2-page-35.htm>.

Naveau, P. Le drame de Septimus et Lucrezia. In S. Harrisson \& J. Aubert (Orgs.). Virginia Woolf: L'ecritures, refuge contre la folie (pp. 101-125). Paris: Michèle.

Citacão/Citation: Alverve, L. A. A. \& Fontenele, L. B. (nov. 2017 a abr. 2018). Estudos psicanalíticos sobre a literatura de Virginia Woolf: alguns apontamentos para futuras pesquisas sobre sua obra. Revista aSEPHallus de Orientação Lacaniana, 13(25), 60-75. Disponível em www.isepol.com/asephallus. doi:

Editor do artigo: Tania Coelho dos Santos.

Recebido/Received: 10/11/2018/11/10/2018.

Aceito/Accepted: 29/01/2019/01/29/2019.

Copyright: (` 2018 Associação Núcleo Sephora de Pesquisa sobre o moderno e o contemporâneo. Este é um artigo de livre acesso, que permite uso irrestrito, distribuição e reprodução em qualquer meio, desde que o autor e a fonte sejam citados/This is an open-access article, which permites unrestricted use, distribution, and reproduction in any medium, provided the author and source are credited. 